\title{
Preparation, characterization, and catalytic studies of Iron and Cobalt complexes supported by ONNO - Tetradentate Schiff-Base ligands
}

\author{
Alekha Kumar Sutar ${ }^{1, *}$, Yasobanta Das ${ }^{2}$, Sasmita Pattanaik $^{1}$, Anita Routaray ${ }^{1}$, Prasanta Rath ${ }^{2}$, \\ Tungabidya Maharana
}

${ }^{1}$ Catalysis Research Lab, Department of Chemistry, Ravenshaw University, Cuttack-3, Odisha, India

${ }^{2}$ School of Applied Sciences (Chemistry), KIIT University, Bhubaneswar, Odisha, India

${ }^{3}$ Department of Chemistry, National Institute of Technology, Raipur, India

\author{
Email address: \\ dralekhasutar@gmail.com(A. K. Sutar)
}

\section{To cite this article:}

Alekha Kumar Sutar, Yasobanta Das, Sasmita Pattanaik, Anita Routaray, Prasanta Rath, Tungabidya Maharana. Preparation,

Characterization, and Catalytic Studies of Iron and Cobalt Complexes Supported by ONNO - Tetradentate Schiff-Base Ligands. American Journal of Applied Chemistry. Vol. 1, No. 2, 2013, pp. 28-36. doi: 10.11648/j.ajac.20130102.13

\begin{abstract}
The free and polymer anchored complexes of iron and cobalt [3-MHBdMBn-M and P-3-MHBdMBn-M], supported by ONNO-tetradentate Schiff-base ligands are prepared by the reactions of metal solution with one molar equivalent of unsupported 3-MHBdMBn (N, N'-bis (2-hydroxy-3-methylbenzaldehyde) 4-Methylbenzene-1,2-diamine) or polymer supported (P-3-MHBdMBn) Schiff-base ligands in methanol. The structural study reveals that iron(III) complex of 3-MHBdMBn Schiff base is octahedral in geometry, whereas, cobalt(II) ions complexes is square planar. Complexation of metal ions increased the thermal stability of 3-MHBdMBn Schiff base. The catalytic activities of metal complexes towards the oxidation of phenol are investigated in the presence of hydrogen peroxide. Experimental results indicate that the reactivity of P-3-MHBdMBn-M is dramatically affected by the polymer support over 3-MHBdMBn-M and iron complexes have greater activity than the cobalt analogue.
\end{abstract}

Keywords: Schiff Base, Polymer Support, Catalysis, Metal Complexes, Phenol, Oxidation

\section{Introduction}

Schiff base complexes of transition metal ions has shown high catalytic activities in various chemical reactions such as oxidation, [1,2] epoxidation of olefins, [3] and polymerization of ethylene to obtain narrow molecular weight distribution, $[4,5]$. However, the polymer-supported analogues of metal complexes showed high catalytic activity $[2,3,6-8]$, and enantioselectivity [6] in comparison to homogeneous catalysts. The manganese (II) salen complexes anchored on tailor-made polymers have more enantioselectivity without any mass transfer limitation for alkenes on polymer supports [9]. The metal complexes were also anchored on other supports, [10-13] but it has been studied that polymeric supports provided better control on efficiency of catalysts [6] due to microenvironment provided by polymer chains for the substrates in comparison to zeolites [14] and silica [15]. The metal complexes on solid supports are immobilized either physically or by forming a covalent bond between metal complexes and supports [6]. Further, the recovery of physically linked catalysts has been found to be low in comparison to covalently bound catalysts due to the leaching of catalysts. The oxidation of phenol using unsupported Schiff base complexes of metal ions is reported [16], but the oxidation of phenol using polymer-supported transition metal complexes was found to be high [17] in the presence of tert-butyl hydroperoxide (t-BHP). The polymer-supported Schiff base complexes of metal ions also showed variations in the decomposition of hydrogen peroxide with their redox potentials [18], which provided a useful criterion to explain the activity of metal ions in the oxidation of phenol in the presence of hydrogen peroxide as the oxidant. The activity of polymer-supported Schiff base complexes of iron(III), cobalt(II) and nickel(II) ions in the oxidation of phenol [19-20] also showed variation with temperature, time, etc, which might be due to the change in concentration of substrate or catalyst. The oxidation of phenol in the presence of metal complexes of 
Salen and hydrogen peroxide as the oxidant is reported, but catalytic activity of metal complexes of N,N'-bis (2-hydroxy -3- methylbenzaldehyde)

4-Methylbenzene-1,2-diamine Schiff base (3-MHBdMBn) Schiff base is not reported in the literature; hence, in these investigations an attempt has been made to prepare polymer-supported metal complexes of 3-MHBdMBn Schiff base and to characterize them for their structures and catalytic activity towards the oxidation of phenol in the presence of hydrogen peroxide as an oxidant.

\section{Experimental}

\subsection{Materials}

Divinyl benzene cross-linked chloromethylated polystyrene beads were obtained from Ion Exchange India Ltd., Mumbai, India and used to anchor synthesized 3-MHBdMBn Schiff base complexes of metal ions. The chloro salts of iron(III) and cobalt(II) ions were purchased from Ranbaxy, Mumbai, India and used without further purifications. The phenol, hydrogen peroxide $(30.0 \mathrm{wt} \%)$, 2-hydroxy-3-methylbenzaldehyde (3-MHBd) and 4-Methylbenzene-1,2-diamine (MBn) were procured form E. Merck, India. Other chemicals and solvents were of analytical grade $(>99.0 \mathrm{wt} \%)$ and used after purifications with standard methods [21].

\subsection{Characterization of 3-MHBdMBn Schiff Base and Its Metal Complexes}

IR spectra of 3-MHBdMBn Schiff base and its metal complexes were recorded on $\mathrm{KBr}$ pellet using Perkin-Elmer 1600 FTIR Spectrophotometer. The electronic spectra of 3-MHBdMBn Schiff base and its metal complexes were recorded with Shimadzu 1601 PC UV-Vis Spectrophotometer by using sample mull in a cuvette. Thermo gravimetric analysis (TGA) of 3-MHBdMBn Schiff base and its metal complexes was carried out using Perkin-Elmer Pyris, Diamond Thermal Analyzer under nitrogen atmosphere at a heating rate of $10^{\circ} \mathrm{C} \mathrm{min}^{-1}$. The loading of metal ions on 3-MHBdMBn Schiff base was determined by analyzing the loading solution with Perkin-Elmer 3100 Atomic Absorption Spectrometer at $\lambda_{\max }$ of corresponding metal ions. The amount of 3-MHBdMBn Schiff base anchored on polymer beads and its composition were estimated using Haraeus Carlo Ebra 1108 Elemental Analyzer. The ${ }^{1} \mathrm{H}-\mathrm{NMR}$ spectra of 3-MHBdMBn Schiff base and its metal complexes were recorded on an FT-NMR-Brucker $300 \mathrm{MHz}$ Spectrometer using DMSO- $\mathrm{d}^{6}$ as a solvent and tetramethylsilane (TMS) as an internal reference. The magnetic moment $(\mu)$ of metal complexes was measured using Vibrating Sample Magnetometer-155. The molecular weight of 3-MHBdMBn Schiff base and its metal complexes was determined using a Vapor Pressure Osmometer (Merck VAPRO 5600, Germany).

\subsection{Synthesis of N, N'-Bis (2-Hydroxy-3-Methyl Benzaldehyde)4-Methylbenzene-1,2-diamine Schiff Base (3-MHBdMBn) and Its Metal Complexes}

3-MHBdMBn Schiff base was synthesized by the modified procedure reported in the literature [21]. The reaction mixture containing

2-hydroxy-3-methylbenzaldehyde (20.00 mmol, $2.72 \mathrm{~g})$ and 4-Methylbenzene-1,2-diamine (10.00 mmol, $1.22 \mathrm{~g})$ in methanol was refluxed at $60^{\circ} \mathrm{C}$ for about $1 \mathrm{hr}$. The reaction mixture on cooling at low temperature produced light orange colored crystals, which were filtered and recrystallized with methanol. The metal complexes of 3-MHBdMBn Schiff base were prepared taking $100 \mathrm{ml}$ methanolic solution of mixture of Schiff base $(20.00 \mathrm{mmol}$, $7.16 \mathrm{~g}$ ) and $20.00 \mathrm{mmol}$ of metal ions in a round bottom flask and refluxing at $60^{\circ} \mathrm{C}$. After $8 \mathrm{~h}$, the solution was cooled and crystalline metal complexes were separated from the mother liquor. Finally, metal complexes were recrystallized in methanol and dried in a vacuum desiccator.

\subsection{Synthesis of Polymer-Anchored N, N'-Bis (2-Hydroxy-3-Methylbenzaldehyde) 4-Methylbenzene-1,2-Diamine (P-3-MHBdMBn) Schiff Base and Its Metal Complexes}

To prepare polymer-anchored metal complexes of 3-MHBdMBn Schiff base, the N, N'-bis (4-amino-2hydroxy-3-methylbenzaldehyde) 4-Methylbenzene-1,2diamine (A-3-MHBdMBn) Schiff base was prepared by carrying out nitrosation and reduction reactions on 3-MHBdMBn Schiff base and then reacting resulted A-3-MHBdMBn Schiff base with cross-linked chloromethylated polystyrene beads. The nitrosation of 3-MHBdMBn Schiff base was carried out using 20.00 mmol (7.16 g) of 3-MHBdMBn Schiff base with sodium nitrite $(20.00 \mathrm{mmol})$ in $1.0 \mathrm{~N}$ hydrochloric acid $(100 \mathrm{ml})$ at $-5^{\circ} \mathrm{C}$. The resultant N, N'-bis (4-nitroso-2-hydroxy3-methylbenzaldehyde) 4-Methylbenzene-1,2-diamine (NO-3-MHBdMBn) was filtered and washed with hot and cold water to remove reaction impurities. The reduction of NO-3-MHBdMBn was carried out using $20.00 \mathrm{mmol}$ of nitrosated Schiff base in $1.0 \mathrm{~N}$ hydrochloric acid $(50 \mathrm{ml})$ in the presence of metallic iron, which produced A-3-MHBdMBn Schiff base. To immobilize the prepared A-3-MHBdMBn Schiff base on cross-linked chloromethylated polystyrene, the methanol swollen polymer beads $(5.0 \mathrm{~g})$ were refluxed in $50 \mathrm{ml}$ methanol containing $20.00 \mathrm{mmol}$ (7.76 g) A-3-MHBdMBn Schiff base. After $8 \mathrm{~h}$, the 3-MHBdMBn Schiff base-anchored polymer beads were separated and dried in a vacuum desiccator. The amount of 3-MHBdMBn Schiff base loaded on polymer beads was estimated with elemental analysis. Subsequently, the metal ions were loaded by keeping 3-MHBdMBn loaded polymer beads $(5.0 \mathrm{~g})$ for $10 \mathrm{~h}$ in an aqueous solution $(50 \mathrm{ml})$ of metal ions $(20.00 \mathrm{mmol})$. Finally, the polymer beads were separated and dried at 
$70^{\circ} \mathrm{C}$ in a vacuum oven after washing with hot and cold water. The loading of metal ions on polymer beads was determined by analyzing the loading solution with an Atomic Absorption Spectrometer. The loading of metal ions on free and polymer-supported 3-MHBdMBn Schiff base was calculated as complexation of metal ions using the amount of 3-MHBdMBn Schiff base taken initially and the amount of metal ions loaded on polymer beads.

\section{Complexation of metal ions $=$ \\ Amount of metal ions loaded Amount of Schiff base used for loading $\times 100$}

\subsection{Catalytic Activity of Metal Complexes in Oxidation of Phenol}

To evaluate the catalytic activity of free and polymersupported metal complexes of 3-MHBdMBn Schiff base, the oxidation of phenol was carried out using hydrogen peroxide as the oxidant at fixed ionic strength $(0.10 \mathrm{M})$ and hydrogen ions concentration $(\mathrm{pH} 7.0)$ in the reaction mixture. To carry out these reactions, a calculated amount of metal-anchored polymer beads were taken in a two-necked round-bottomed flask containing $0.05 \mathrm{M}$ phenol (4.70 g). The oxidation of phenol was carried out by adding $5.67 \mathrm{~g}(0.05 \mathrm{M})$ hydrogen peroxide $(30.0 \mathrm{wt} \%)$ in the reaction mixture and $2.0 \mathrm{ml}$ chlorobenzene as an internal standard. The water condenser and supply of nitrogen were attached with reaction flask before starting the heating and stirring (1200 rpm) of reaction mixture. Gas chromatography was used to follow these reactions at different time intervals. The retention time of standards was used to identify the reaction products, and product selectivity was measured using peak areas of reaction products in the chromatograms. The reactions were also carried out taking different molar ratios of substrates, hydrogen peroxide, and catalyst. The rate of oxidation for the oxidation of phenol was determined by studying reactions at different temperatures and at constant molar ratios of substrate to $\mathrm{H}_{2} \mathrm{O}_{2}$ and catalyst. The reactions were also studied without using catalysts to analyze the effect of catalysts in the oxidation of phenol.

\section{Results and Discussion}

Investigations have revealed that polymer-supported metal complexes are sometimes more catalytic and efficient than free and unsupported analogs [38]. The activity of catalysts also showed dependence on properties of polymer supports [39] and amount of loaded catalysts [40,41]. Thermal stability of catalysts is required to be high, if these catalysts have to be applied in high temperature reactions. Therefore, thermal analysis of supported metal complexes was carried out to evaluate their possible applications in high temperature reactions and to provide a proof for complexation of metal ions with polymer-anchored 3-MHBdMBn Schiff base. The TGA of polymer supported 3-MHBdMBn Schiff base showed a weight loss of $40.4 \mathrm{wt} \%$ at $500^{\circ} \mathrm{C}$, but its iron(III) and cobalt(II) ion complexes showed a weight loss of 25.2 and $35.1 \mathrm{wt} \%$, respectively at same temperature, which was clear indication that iron(III) ion complexes were more stable in comparison to cobalt(II) ions (Figure 1). The weight loss at $500^{\circ} \mathrm{C}$ was attributed to the decomposition of metal complexes of 3-MHBdMBn Schiff base.

In addition to thermal analysis, the free and polymer-supported metal complexes of 3-MHBdMBn Schiff base were also characterized by IR and UV techniques to provide a proof for the complexation of metal ions and to decide the structures and geometries of metal complexes on the basis of elemental analysis and magnetic properties of metal complexes.

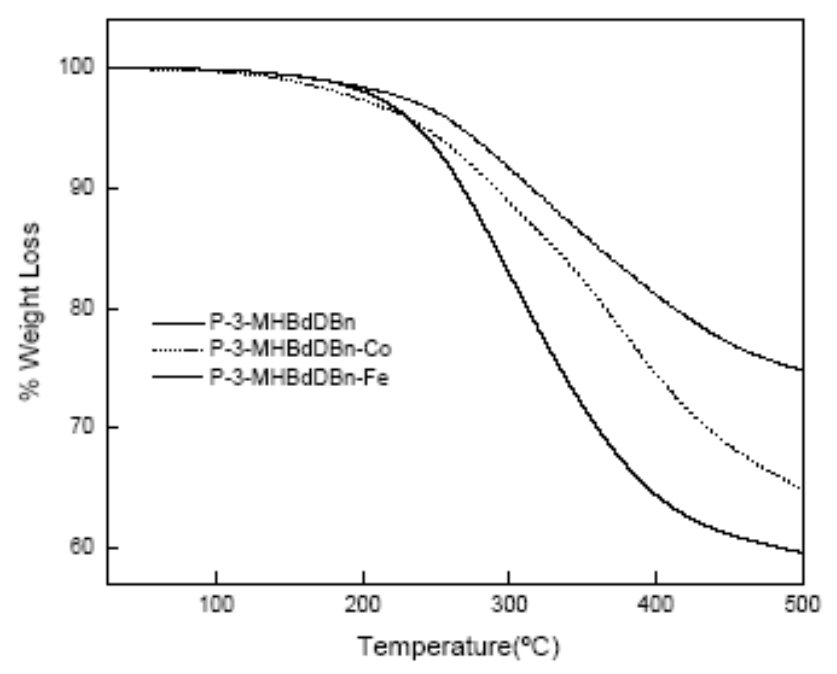

Figure 1. Thermal stability of polymer-supported 3-MHBdMBn Schiff base and its metal complexes

\subsection{Characterization of $N, N^{\prime}-B i s$ (2-hydroxy-3- Methylbenzaldehyde) 4-Methylbenzene-1, 2-Diamine (3-MHBd MBn) Schiff base}

The 3-MHBdMBn Schiff base was obtained by refluxing 2-hydroxy-3-methylbenzaldehyde (3-MHBd) and 4-Methylbenzene-1,2-diamine (MBn) for $1 \mathrm{hr}$ at $60^{\circ} \mathrm{C}$ in methanol, which produced a substantial yield (86.2 wt\%) (Scheme 1). The IR spectrum (Figure 2) of 3-MHBdMBn Schiff base showed absorption bands at $1610 \mathrm{~cm}^{-1}(>C=N)$, $1268 \mathrm{~cm}^{-1}(>\mathrm{C}-\mathrm{O})$ phenolic (Figure 2) and a broad band between 3350 and $2910 \mathrm{~cm}^{-1}$ was also observed, which was assigned to phenolic $\mathrm{OH}$. The elemental analysis of 3-MHBdMBn Schiff base showed (wt $\%$ ): $\mathrm{C}=76.64, \mathrm{~N}=$ 8.06 and $\mathrm{H}=5.79$; Caltd (\%): $\mathrm{C}=77.07, \mathrm{~N}=7.82$ and $\mathrm{H}=$ 6.19, which corresponded to $\mathrm{C}_{23} \mathrm{H}_{22} \mathrm{~N}_{2} \mathrm{O}_{2}$ empirical formula of 3-MHBdMBn Schiff base.

The molecular weight of Schiff base was $357.37 \mathrm{~g} \mathrm{~mol}^{-1}$ (Caltd $358.43 \mathrm{~g} \mathrm{~mol}^{-1}$ ). The electronic spectra of 3-MHBdMBn Schiff base (Figure 3) showed absorption bands at $284 \mathrm{~nm}$ and $346 \mathrm{~nm}$, which were assigned to $\pi \rightarrow$ $\pi^{*}$ and $\mathrm{n} \rightarrow \pi^{*}$ transitions. The $1 \mathrm{H}-\mathrm{NMR}$ spectrum of the Schiff base showed signals at $\delta / \mathrm{ppm}=2.52(6 \mathrm{H}), 2.83(3 \mathrm{H})$, $5.15(2 \mathrm{H}), 6.91(2 \mathrm{H}), 7.27(2 \mathrm{H}), 7.41(3 \mathrm{H}), 7.60(2 \mathrm{H})$, and 
$8.66(2 \mathrm{H})$ which corresponded to the structure of 3-MHBdMBn Schiff base.

\subsection{Synthesis and Characterization of $N, N^{\prime}$-bis (4-Amino -2-Hydroxy-3-Methylbenzaldehyde) \\ 4-Methylbenzene-1, 2- Diamine (A-3-MHBdMBn) Schiff Base and Its Anchoring on Polymer Beads}

The nitrosation of 3-MHBdMBn Schiff base was carried out in the presence of $\mathrm{NaNO}_{2} / \mathrm{HCl}$, which gave $86.5 \%$ yield of N, N'-bis (4-nitroso-2-hydroxy-3- methylbenzaldehyde) 4-Methylbenzene-1,2-diamine (NO- 3-MHBdMBn) (Scheme 2). The elemental analysis of $\mathrm{N}, \mathrm{N}^{\prime}$-bis (4-nitroso-2-hydroxy-3-methylbenzaldehyde)

4-Methylbenzene-1,2-diamine showed (wt $\%): \quad \mathrm{C}=67.00$, $\mathrm{N}=12.63$, and $\mathrm{H}=5.00 ; \quad$ Caltd (wt\%): $\mathrm{C}=66.34$, $\mathrm{N}=13.45$, and $\mathrm{H}=4.84$, which corresponded to $\mathrm{C}_{23} \mathrm{H}_{20} \mathrm{~N}_{4} \mathrm{O}_{4}$ formula of nitrosated Schiff base. The molecular weight of NO-3-MHBdMBn was $415.03 \mathrm{~g} \mathrm{~mol}^{-1}$ (Caltd $416.43 \mathrm{~g} \mathrm{~mol}^{-1}$ ). The IR spectrum of NO-3-MHBdMBn showed absorption bands at $1607 \mathrm{~cm}^{-1}$ $(>\mathrm{C}=\mathrm{N}), 1266 \mathrm{~cm}^{-1}(>\mathrm{C}-\mathrm{O})$ phenolic, and $1530 \mathrm{~cm}^{-1}$ and $1320 \mathrm{~cm}^{-1}$ for $\mathrm{N}-\mathrm{O}$ group. The nitrosation of 3-MHBdMBn Schiff base showed a shift in NMR signals in comparison to NMR signals observed with pure 3-MHBdMBn Schiff base. The nitrosated $3-M H B d M B n$ Schiff base showed proton signals at $\delta / \mathrm{ppm}$ $=2.54(6 \mathrm{H}), 2.88(3 \mathrm{H}), 5.15(2 \mathrm{H}), \quad 7.35(2 \mathrm{H}), \quad 7.42(3 \mathrm{H})$, $7.96(2 \mathrm{H})$, and $8.69(2 \mathrm{H})$, which corresponded to the structure of nitrosated 3-MHBdMBn Schiff base. The protons ortho to nitroso group in 3-MHBdMBn Schiff base were deshielded; hence, their signals appeared at 7.35 and $7.96 \mathrm{ppm}$ in place of 7.27 and $7.60 \mathrm{ppm}$ respectively, of pure 3-MHBdMBn Schiff base. The proton signal at 6.91 ppm was missing due to the substitution of nitroso group in the benzene. The NO-3-MHBdMBn was reduced with iron(III) ions in the presence of hydrochloric acid, which gave $81.3 \mathrm{wt} \%$ yield of A-3-MHBdMBn Schiff base. The elemental analysis of A-3-MHBdMBn Schiff base showed (wt \%): $\mathrm{C}=70.54, \quad \mathrm{~N}=13.00$, and $\mathrm{H}=7.02, \quad$ Caltd $(\mathrm{wt} \%): \quad \mathrm{C}=71.11, \quad \mathrm{~N}=14.42$, and $\mathrm{H}=6.23$, which corresponded to $\mathrm{C}_{23} \mathrm{H}_{24} \mathrm{~N}_{4} \mathrm{O}_{2}$ empirical formula of Schiff base. The molecular weight of A-3-MHBdMBn Schiff base was found to be $387.23 \mathrm{~g}$ $\mathrm{mol}^{-1}$ (Caltd $388.46 \mathrm{~g} \mathrm{~mol}^{-1}$ ). The IR spectrum of A-3-MHBdMBn Schiff base showed absorption bands at $1605 \mathrm{~cm}^{-1}(>\mathrm{C}=\mathrm{N}), 1263 \mathrm{~cm}^{-1}(>\mathrm{C}-\mathrm{O})$ phenolic, and a band between 1632 and $1618 \mathrm{~cm}^{-1}$ for $>\mathrm{C}-\mathrm{N}$ group. The 1H-NMR spectrum of A-3-MHBdMBn Schiff base showed proton signals at $\delta / \mathrm{ppm}=2.52(6 \mathrm{H})$, $2.85(3 \mathrm{H}), 4.15(4 \mathrm{H}), 5.15(2 \mathrm{H}), 6.36(2 \mathrm{H}), \quad 7.42(3 \mathrm{H})$, $6.81(2 \mathrm{H})$, and $8.69(2 \mathrm{H})$, which corresponded to the structure of A-3-MHBdMBn Schiff base.

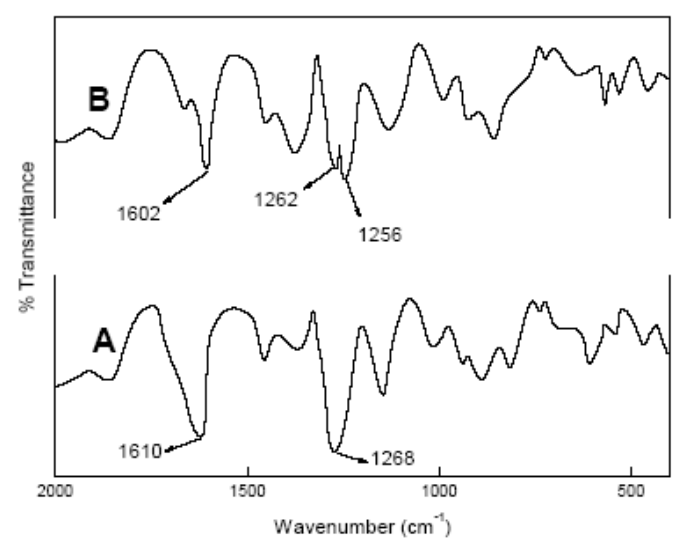

Figure 2. FTIR spectra of unsupported 3-MHBdDBn Schiff base (A) \& polymer supported 3-MHBdDBn Schiff base (B).

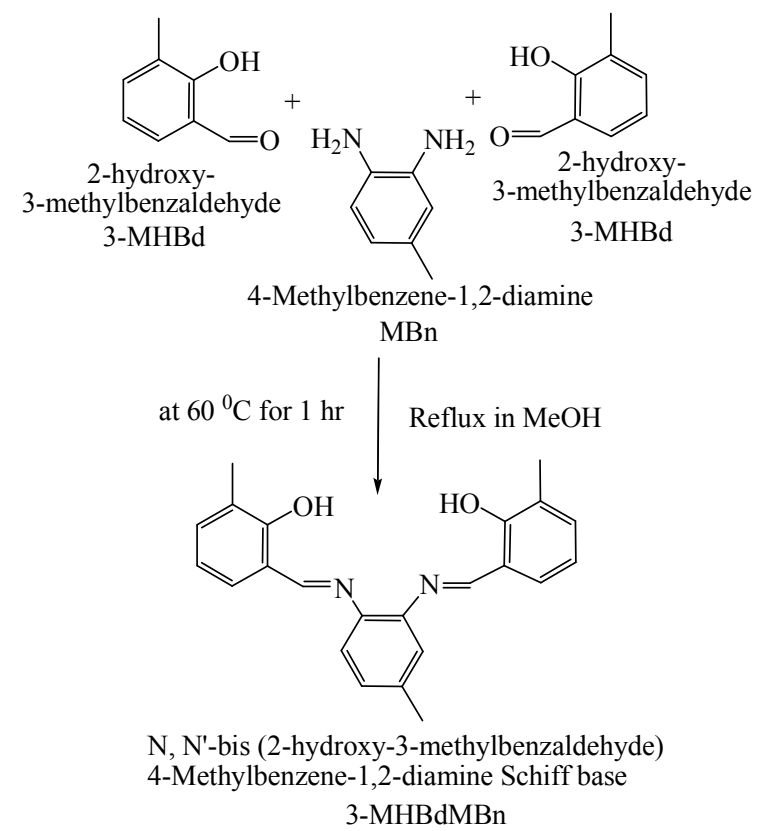

Scheme 1. $N$, N'-bis (2-hydroxy-3-methylbenzaldehyde) 4-Methylbenzene -1,2-diamine (3-MHBdMBn) Schiff base

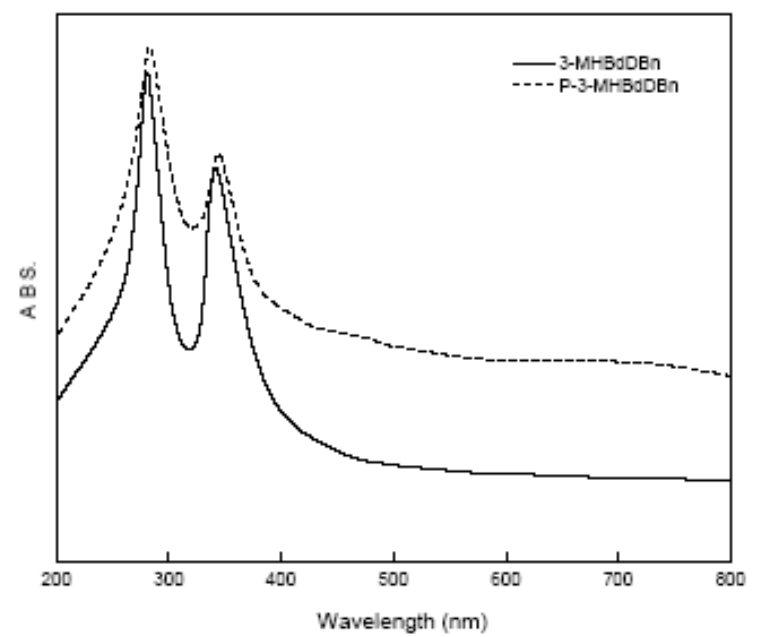

Figure 3. Electronic spectra of unsupported and polymer supported 3-MHBdDBn Schiff base 
The synthesized Schiff base was anchored on cross-linked chloromethylated polystyrene beads by refluxing A-3-MHBdMBn Schiff base with polymer beads in DMF for $8 \mathrm{~h}$ at $60^{\circ} \mathrm{C}$. The amount of A-3-MHBdMBn Schiff base anchored on polymer beads was $87.0 \mathrm{wt} \%$ (Scheme 3). The anchoring of A-3-MHBdMBn Schiff base on polymer beads was confirmed by comparing the IR spectrum of 3-MHBdMBn Schiff base anchored polymer beads with IR spectrum of pure polymer beads. The IR spectrum of polymer-anchored Schiff base showed new absorption bands at $1602 \mathrm{~cm}^{-1}(>\mathrm{C}=\mathrm{N}), 1260 \mathrm{~cm}^{-1}(>\mathrm{C}-\mathrm{O})$ phenolic, and a broadband between 1629 and $1610 \mathrm{~cm}^{-1}$ $(>\mathrm{C}=\mathrm{N})$, which were absent in the IR spectrum of pure polymer beads, but were present in free Schiff base. The IR spectrum of pure polymer beads showed absorption band at $1262 \mathrm{~cm}^{-1}$, which is attributed to $\mathrm{C}-\mathrm{Cl}$ bond of chloromethyl in cross-linked polymer beads. The decrease in the intensity of absorption band at $1262 \mathrm{~cm}^{-1}$ in polymeranchored 3-MHBdMBn Schiff base than pure polymer beads was an evidence for anchoring of 3-MHBdMBn Schiff base on polymer beads. The appearance of new absorption bands and shift in characteristic absorption bands of 3-MHBdMBn Schiff base were also used as evidence for anchoring of 3-MHBdMBn Schiff base on polymer beads.
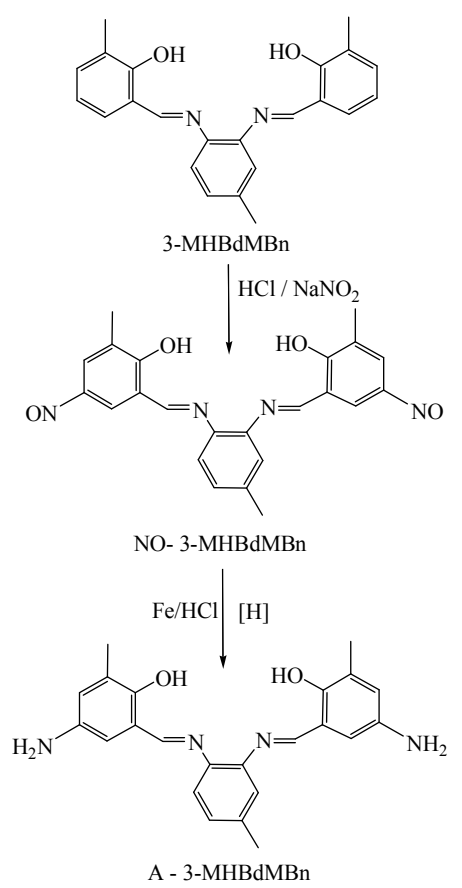

Scheme 2. Synthesis of $N, N^{\prime}$-bis (4-amino-2-hydroxy-3- methyl benzaldehyde) 4-Methylbenzene-1,2-diamine (A-3-MHBdMBn) Schiff base

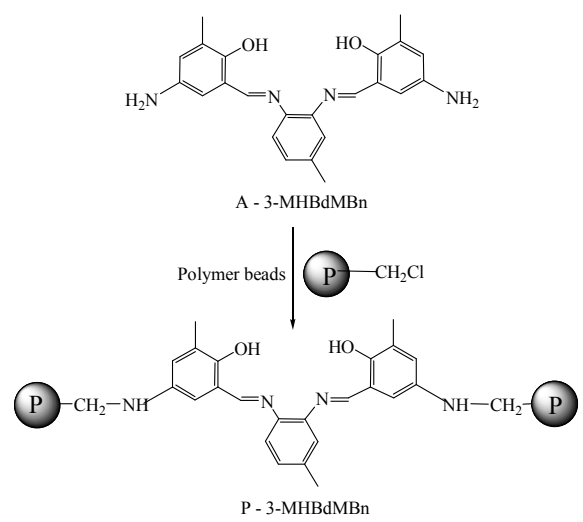

Scheme 3. Synthesis of polymer-anchored Schiff base (P-3-MHBdMBn)

\subsection{Characterization of Free and Polymer-Anchored Metal Complexes of 3-MHBdMBn Schiff base}

The loading of metal ions on free and polymer-supported 3-MHBdMBn Schiff base was carried out by refluxing free Schiff base (Scheme 4) and polymer-anchored Schiff base in solution of metal salt at $60^{\circ} \mathrm{C}$ for $6 \mathrm{~h}$ (Scheme 5). The metal complexes of free Schiff base (3-MHBdMBn-M) and polymer-anchored Schiff base (P-3-MHBdMBn -M) after separation and purification were analyzed for their structures and loading of metal ions. The complexation of iron(III) ions on free 3-MHBdMBn Schiff base and polymer-anchored Schiff base was 77.71 and $82.81 \mathrm{wt} \%$, whereas for cobalt(II) ions 74.85 and $83.99 \mathrm{wt} \%$ respectively (Table 1). These results have clearly suggested that the loading of metal ions on polymer-supported 3-MHBdMBn Schiff base was higher than free 3-MHBdMBn Schiff base.
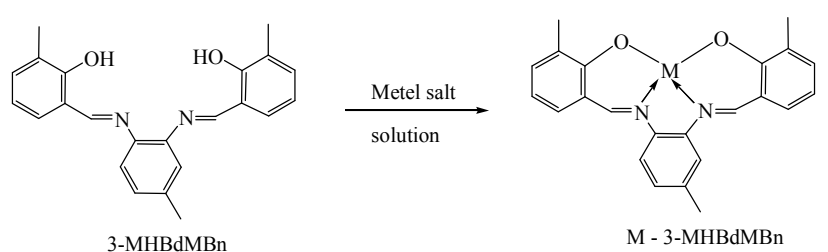

Scheme 4. Loading of metal ions on unsupported HPPn Schiff base

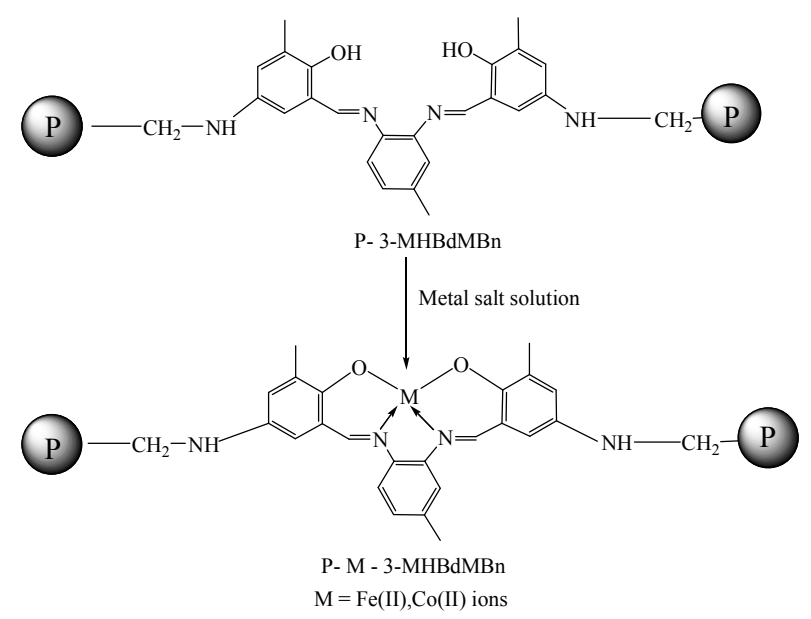

Scheme 5. Loading of metal ions on polymer-supported Schiff base (P-3-MHBdMBn-M) 
Table 1. Efficiency of complexation (EC) of metal ions (wt\%)

\begin{tabular}{lcc}
\hline Metal ions & $\begin{array}{c}\text { Unsupported } \\
\text { 3-MHBdMBn Schiff base }\end{array}$ & $\begin{array}{c}\text { Polymer supported } \\
\text { 3-MHBdMBn Schiff } \\
\text { Fe(III) ions }\end{array}$ \\
bo(II) ions & 77.71 & 82.81 \\
\hline
\end{tabular}

$[3-\mathrm{MHBdMBn}]=20 \mathrm{mmol}$, [Metal ions $]=20 \mathrm{mmol}$.

The complexation of metal ions with 3-MHBdMBn Schiff base showed significant variations in IR bands for $>\mathrm{C}=\mathrm{N}$ and $>\mathrm{C}-\mathrm{O}$ groups and new absorption bands appeared due to the formation of $\mathrm{M}-\mathrm{O}$ and $\mathrm{M}-\mathrm{N}$ bonds in metal complexes. The disappearance of phenolic absorption band between 2910 and $3350 \mathrm{~cm}^{-1}$ in the IR spectrum of 3-MHBdMBn Schiff base after the complexation of metal ions was an evidence for the complexation of metal ions with 3-MHBdMBn Schiff base. The polymer-supported Schiff base showed absorption bands at low frequency (Figure 2B) in comparison to free Schiff base (Figure 2A). On complexation with iron(III) ions, the frequency of $>\mathrm{C}=\mathrm{N}$ absorption band of free Schiff base has decreased from 1610 to $1605 \mathrm{~cm}^{-1}$, whereas polymer- supported Schiff base showed variation from 1602 to $1601 \mathrm{~cm}^{-1}$ (Figure 4).

Complexation of cobalt(II) with free Schiff base and polymer-supported Schiff base showed absorption bands at $1593 \mathrm{~cm}^{-1}$ and $1589 \mathrm{~cm}^{-1}$, respectively (Figure 4). These variations in IR band corresponding to $>\mathrm{C}=\mathrm{N}$ group of 3-MHBdMBn Schiff base were used as evidence for interactions of metal ions with azomethine nitrogen $(>C=N)$ of 3-MHBdMBn Schiff base. The complexation of iron(III) ions showed new absorption band at $424 \mathrm{~cm}^{-1}$ with free Schiff base and at $420 \mathrm{~cm}^{-1}$ with polymer-anchored Schiff base, which was due to the formation of $\mathrm{M}-\mathrm{N}$ bond between iron(III) ions and Schiff base. The complexation of cobalt(II) ions showed absorption band at $416 \mathrm{~cm}^{-1}$ and 411 $\mathrm{cm}^{-1}$ for $\mathrm{M}-\mathrm{N}$ bond with free and polymer-supported 3-MHBdMBn Schiff base. The complexation of iron(III) and cobalt(II) ions showed another new band due to the formation of bond between metal ions and phenolic oxygen (-O-M). The complexation of iron(III) and cobalt(II) ions with polymer-supported 3-MHBdMBn Schiff base produced $\mathrm{M}-\mathrm{O}$ absorption band at $537 \mathrm{~cm}^{-1}$ and $559 \mathrm{~cm}^{-1}$ (Figure 4). The complexation of metal ions with Schiff base was further confirmed by comparing electronic spectra of metal complexes and pure 3-MHBdMBn Schiff base. The complexation of iron(III) ions with 3-MHBdMBn Schiff base showed variation in $\pi \rightarrow \pi^{*}$ transition from $284 \mathrm{~nm}$ to $254 \mathrm{~nm}$, but in the case of cobalt(II) ions, the $\pi \rightarrow \pi^{*}$ transition appeared at $243 \mathrm{~nm}$ (Table 2). The $\mathrm{n} \rightarrow \pi{ }^{*}$ transition of 3-MHBdMBn Schiff base was changed from $346 \mathrm{~nm}$ to $310 \mathrm{~nm}$ on complexation with iron(III) ions, whereas in the case of cobalt(II) the $\mathrm{n} \rightarrow \pi^{*} \quad$ transition appeared at $299 \mathrm{~nm}$. The charge transfer $(\mathrm{CT})$ and $\mathrm{d} \rightarrow \mathrm{d}$ transitions were also used as evidence for complexation of metal ions with Schiff base. The complexation of cobalt(II) ions with 3-MHBdMBn
Schiff base showed CT transition at $363 \mathrm{~nm}$, but no CT transition was shown by iron(III) ions complex. The complexation of iron(III) with HPPn Schiff base showed $\mathrm{d} \rightarrow \mathrm{d}$ transitions at $459 \mathrm{~nm}$ but no $\mathrm{d} \rightarrow \mathrm{d}$ transition was observed with cobalt(II) ions. These electronic transitions corresponded to $t_{2 g}^{5} e_{g}^{0}$ and $t_{2 g}{ }^{6}$ $\mathrm{e}_{\mathrm{g}}{ }^{1}$ configurations for iron(III) and cobalt(II) ions in these complexes.

Table 2. Electronic transitions in unsupported and polymer supported metal ions complexes of 3-MHBdMBn Schiff base

\begin{tabular}{ccccc}
\hline & \multicolumn{5}{c}{ Frequencies $\boldsymbol{\lambda}_{\max } / \mathbf{n m}$} \\
Compounds & $\pi \rightarrow \pi *$ & $\mathbf{n} \rightarrow \pi *$ & $\mathbf{C} \rightarrow \mathbf{T}$ & $\mathbf{d} \rightarrow \mathbf{d}$ \\
3-MHBdMBn & 284 & 346 & - & 459 \\
P-3-MHBdMBn & 281 & 341 & - & 451 \\
3-MHBdMBn -Fe & 254 & 310 & - & - \\
P-3-MHBdMBn -Fe & 251 & 305 & - & - \\
3-MHBdMBn -Co & 243 & 299 & 363 & - \\
P-3-MHBdMBn -Co & 239 & 293 & 352 & - \\
\hline
\end{tabular}

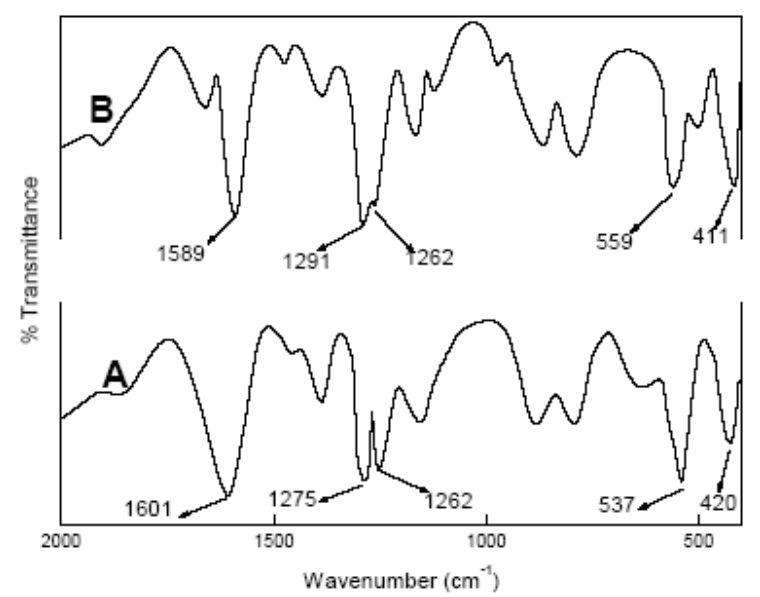

Figure 4. FTIR spectra of polymer supported 3-MHBdDBn-Fe complex (A) and polymer supported 3-MHBdDBn-Co complex

The magnetic moment $(\mu)$ of Schiff base complexes of iron(III) and cobalt(II) ions was found to be 1.99 and 1.86 $\mathrm{BM}$, respectively, which indicated that iron(III) and cobalt(II) ions complexes were paramagnetic in nature with one unpaired electron in each. The magnetic moment $(\mu)$ and electronic configurations have suggested an octahedral structure with $\mathrm{d}^{2} \mathrm{sp}^{3}$ hybridization for iron(III) ions complexes and square planar structure with $\mathrm{dsp}^{2}$ hybridization for cobalt(II) ions complexes (Scheme 6).

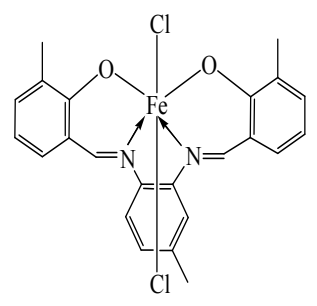

Fe - 3-MHBdMBn (Octahedral)

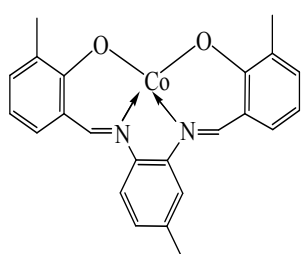

Co- 3-MHBdMBn (Square planar)

Scheme 6. Geometry and structure of 3-MHBdMBn Schiff base complexes of metal ions 


\subsection{Oxidation of Phenol}

The catalytic activity of free and polymer-supported metal complexes of 3-MHBdMBn Schiff base was evaluated by studying the oxidation of phenol in the presence of hydrogen peroxide. The gas chromatographic analysis was used to determine the product selectivity and to estimate the percent conversion of phenol. The catechol (CTL) was a major reaction product in the oxidation of phenol (Scheme 7). The formation of reaction products was attributed to enzymatic behaviour of metal complexes of 3-MHBdMBn Schiff base.

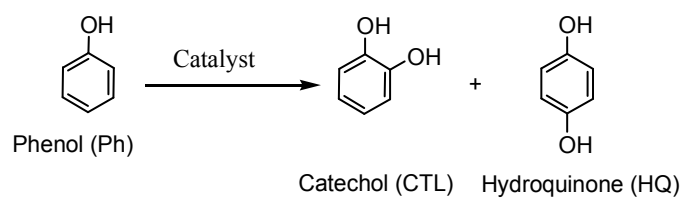

Scheme 7. Oxidation of phenol

The polymer support has facilitated the decomposition of these intermediates; hence, per cent conversion of phenol was more with polymer-supported metal complexes (Figure 5 ) in comparison to free metal complexes of 3-MHBdMBn Schiff base (Table 3). The conversion of phenol was initially high at $240 \mathrm{~min}$ and then after the conversion became almost constant due to substantial decrease in the concentration of oxidant and substrate in the reaction mixture (Table 3). Similar trends in substrate conversion were observed with supported catalysts at different time intervals as found with unsupported catalysts (Figure 5). The oxidation reaction also shown dependence on type of catalyst as it is clear from substrate conversion in the presence of 3-MHBdMBn Schiff base complexes of iron(III), and cobalt(II) ions (Table 3). The percent conversion of phenol was more with Schiff base complexes of iron(III) ions in comparison to cobalt(II) ion complex. The high activity of metal complexes on polymer support was due to the facile interactions of catalyst with substrate than with unsupported catalysts. The low activity of catalyst in solution was due to the formation of inactive dimers or multimers of metal complexes in the solution. The amount of phenol oxidized with hydrogen peroxide was almost equal to the sum of amount of CTL and hydroquinone (HQ) produced, which discarded the formation of other reaction products such as polymeric phenols.

The amount of CTL and HQ was equal to phenol conversion, but reaction showed high selectivity for CTL. The supported catalysts were recycled and also further evaluated for their catalytic activity after their applications in oxidation reactions. The efficiency of supported catalysts remained almost constant upto six recycles and then the efficiency decreased (Table 4). The product selectivity for CTL remained unaffected on using recycled catalysts, which was an indication for the structural stability of metal complexes on polymer support as confirmed by comparing
IR spectra of recycled catalysts with IR spectra of freshly prepared catalysts. The activity of metal complexes in substrate conversion and product selectivity was evaluated at different molar ratios of substrate to hydrogen peroxide and catalyst.

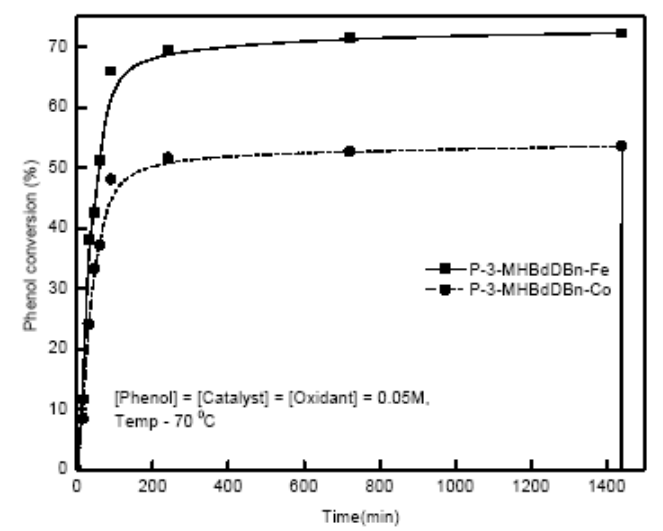

Figure 5. Effect of reaction time on oxidation of phenol in presence of polymer-supported metal complexes. [Phenol]:[Catalyst]: $\left[\mathrm{H}_{2} \mathrm{O}_{2}\right]=1: 1: 1$ (0.05M), Temp. $=70{ }^{\circ} \mathrm{C}$.

The rate of phenol conversion was high $\left(2.41 \times 10^{-6}\right.$ mole $\left.\mathrm{dm}^{-3} \mathrm{~s}^{-1}\right)$ in the presence of polymer-supported 3-MHBdMBn Schiff base complexes of iron(III) ions than Schiff base complexes of cobalt(II), which showed the rate of phenol conversion as $1.79 \times 10^{-6}$ mole $\mathrm{dm}^{-3} \mathrm{~s}^{-1}$ (Table 5). The rate of phenol conversion and selectivity for CTL was low with free 3-MHBdMBn Schiff base complexes of metal ions. The turnover number (TON) for the oxidation of phenol was high $\left(16.33 \mathrm{~g} \mathrm{~mol}^{-1} \mathrm{Fe} \mathrm{hr}^{-1}\right)$ in the presence of 3-MHBdMBn Schiff base complexes of iron(III) ions in comparison to Schiff base complexes of cobalt(II) (12.14 g $\mathrm{mol}^{-1} \mathrm{Co} \mathrm{hr}^{-1}$ ) at a molar ratio of $1: 1: 1$ of $\mathrm{H}_{2} \mathrm{O}_{2}$ to phenol and catalyst (Table 5). The rate of substrate conversion and TON in the oxidation of phenol varied significantly with molar ratio of hydrogen peroxide but product selectivity in both cases remained almost constant (Tables 5).

Table 3. Catalytic activity of unsupported metal complexes (M-3-MHBd $\mathrm{MBn}$ ) in oxidation of phenol (Ph)

\begin{tabular}{ccc}
\hline & Percent conversion (wt \%) of Phenol & \\
Time/min & Fe-3-MHBdMBn & Co-3-MHBdMBn \\
0 & 0.0 & 0.0 \\
15 & 7.4 & 2.3 \\
30 & 12.9 & 6.2 \\
45 & 20.6 & 10.5 \\
60 & 27.2 & 14.8 \\
90 & 42.0 & 26.4 \\
240 & 48.4 & 32.5 \\
720 & 49.9 & 34.1 \\
1440 & 51.0 & 35.0 \\
\hline
\end{tabular}

[Phenol]:[Catalyst]: $\left[\mathrm{H}_{2} \mathrm{O}_{2}\right]=1: 1: 1(0.05 \mathrm{M})$, Temp. $=70{ }^{\circ} \mathrm{C} . \mathrm{CH}_{3} \mathrm{CN}=2.0$ $\mathrm{mL}$. 
Table 4. Efficiency of recycled supported catalysts (P-3-MHBdMBn-M) in oxidation of phenol.

\begin{tabular}{cccccccc}
\hline & & \multicolumn{3}{c}{ Recycle number } \\
Supported metal complexes & & $\mathbf{0}$ & $\mathbf{2}$ & $\mathbf{4}$ & $\mathbf{6}$ & $\mathbf{8}$ \\
& P-3-MHBdMBn -Fe & Conversion & 72.3 & 72.0 & 71.7 & 68.0 & 51.0 \\
& Selectivity & 95.1 & 95.3 & 95.1 & 92.3 & 90.1 \\
P-3-MHBdMBn-Co & Conversion & 53.6 & 53.1 & 52.4 & 50.2 & 39.5 \\
& Selectivity & 93.8 & 93.9 & 92.7 & 90.4 & 88.0 \\
\hline
\end{tabular}

[Phenol]:[Catalyst]: $\left[\mathrm{H}_{2} \mathrm{O}_{2}\right]=1: 1: 1(0.05 \mathrm{M})$, Temp. $=70{ }^{\circ} \mathrm{C} . \mathrm{CH}_{3} \mathrm{CN}=2.0 \mathrm{~mL}$

Table 5. Oxidation of phenol by metal ions complexes of polymer supported 3-MHBdMBn Schiff base: Phenol conversion, selectivity for catechol and kinetic parameters

\begin{tabular}{cccccccccc}
\hline & \multicolumn{3}{c}{ Unsupported catalyst } & \multicolumn{5}{c}{ Polymer-supported catalyst } \\
Complexes & Conversion (wt\%) & $\begin{array}{c}\text { Selectivity } \\
(\mathbf{w t} \%)\end{array}$ & TON & $\mathbf{R}_{\mathbf{p}}$ & $\begin{array}{c}\text { Conversion } \\
(\mathbf{w t} \%)\end{array}$ & $\begin{array}{c}\text { Selectivity } \\
(\mathbf{w t} \%)\end{array}$ & TON & $\mathbf{R}_{\mathbf{p}}$ \\
Iron & 50.5 & 96.5 & 11.37 & 1.68 & 72.3 & 95.3 & 16.33 & 2.41 \\
Cobalt & 35.2 & 90.3 & 7.63 & 1.13 & 53.6 & 93.9 & 12.14 & 1.79 \\
\hline
\end{tabular}

$\left[\mathrm{H}_{2} \mathrm{O}_{2}\right] /[\mathrm{Phenol}] /[$ Catalyst $]=0.05 \mathrm{M}$, Time $=1440 \mathrm{~min}$,Temp. $=70{ }^{0} \mathrm{C} \mathrm{CH}_{3} \mathrm{CN}=2.0 \mathrm{~mL}$ TON in terms of $=\mathrm{g} \mathrm{mol}^{-1} \mathrm{M} \mathrm{hr}^{-1}$, Rate of oxidation $\left(\mathrm{R}_{\mathrm{p}}\right)$ in terms of $=10^{-6} \mathrm{~mole} \mathrm{dm}^{-3} \mathrm{~s}^{-1}$

\subsection{Mechanism for Oxidation of Phenol}

Considering the experimental findings for the oxidation of phenol with free and supported 3-MHBdMBn Schiff base complexes of metal ions, the following reaction steps are proposed (Scheme 8 ). The free and polymer-supported Schiff base complexes of metal ions (3-MHBdMBn-M) have produced active species (M-3-MHBdMBn-HOO-) through fast interactions with hydrogen peroxide and 3-MHBdMBn Schiff base. The active species was subsequently used in the formation of intermediates ((M-3-MHBdMBn-Ph-HOO-) through its interactions with phenol in a rapid equilibrium (k). The intermediate (M-3-MHBdMBn-Ph-HOO') has facilitated the nucleophilic attack of ${ }^{-} \mathrm{OOH}$ species on ortho and para position on phenol to produce hydroxy-substituted phenols (Scheme 7). The reaction products, catalyst and hydroxyl ions were formed through decomposition of intermediates (Scheme 8 step 4) and finally the hydroxyl ions reacted with hydrogen ions, which were produced in step 1 .

\section{Conclusion}

The polymer-supported transition metal complexes of 3-MHBdMBn Schiff base were synthesized and characterized successfully for their structures and catalytic activity in the oxidation of phenol. The polymer-supported 3-MHBdMBn Schiff base complexes of metal ions showed high catalytic activity than free metal complexes. The Schiff base complexes of iron(III) ions were more active in the conversion of phenol than cobalt(II) ions. The oxidation of phenol showed high selectivity for CTL. The supported catalysts showed high rate of oxidation and TON than unsupported catalysts, which clearly suggested that polymer support has played a significant role in increasing the rate for oxidation of phenol in the presence of metal complexes of 3-MHBdMBn Schiff base.

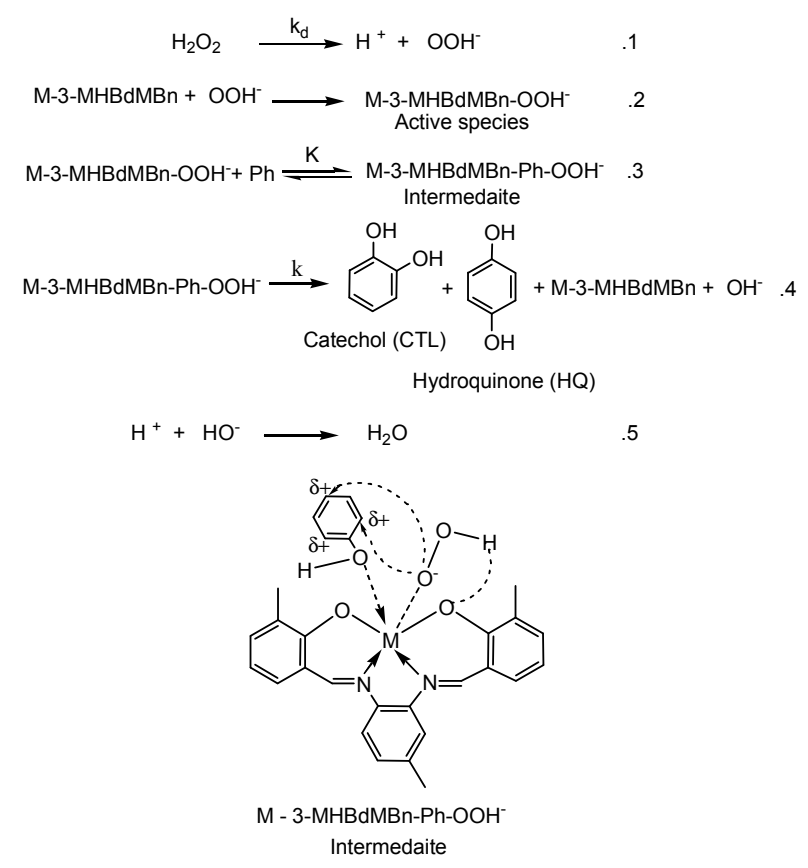

Scheme 8. Reaction steps of oxidation of phenol

\section{Acknowledgments}

One of the authors Ms. A Routaray is thankful to DST, India for providing Fellowship. The authors are also grateful to Ravenshaw University, KIIT University and National Institute of Technology, Raipur for providing research facilities.

\section{References}

[1] J. Tong, Y. Zhang, Z. Li, C. Xia. "Highly effective catalysts 
of natural polymer supported salophen $\mathrm{Mn}$ (III) complexes for aerobic oxidation of cyclohexane." J. Mol. Catal. A: Chem. 2006; 249: 47-52.

[2] K. C. Gupta, A. K. Sutar, "Catalytic activities of Schiff base transition metal complexes." Coord. Chem. Rev. 2008; 252(12-14):1420-1450.

[3] S. Tangestaninejad, M. H. Habibi, V. Mirkhani, M. Moghadam, G. Grivani, "Simple preparation of some reusable and efficient polymer supported tungsten carbonyl catalysts and clean epoxidation of cis-cyclooctene in the presence of H2O2." J. Mol. Catal. A: Chem. 2006; 255: 249-253.

[4] A. K. Sutar, T. Maharana, S. Dutta, Chi-Tien Chen, Chu-Chieh Lin, "Ring-opening polymerization by lithium catalysts: an overview." Chem. Soc. Rev., 2010, 39, $1724-1746$

[5] Y. Nakayama, H. Bando, Y. Sonobe, T. Fuzita, "Olefin polymeri- zation behavior of bis (phenoxy-imine) Zr, Ti and V com- plexes with $\mathrm{MgCl} 2$-based cocatalysts.” J. Mol. Catal. A: Chem. 2004; 213: 141-1150.

[6] K. C. Gupta, A. K. Sutar, C. C. Lin, "Polymer supported Schiff base complexes in oxidation reactions." Coord. Chem. Rev. 2009; 253:1926-1946.

[7] A. Akelah, A. Rehab, ER. Kenawy, MS. Zeid, MS. Abou, "Catalytic activity of polymer-montmorillonites in chemical reactions.” J. Appl. Polym. Sci. 2006; 101: 1121-1129.

[8] R. S. Drago, J. Gaul, A. Zombeck, D. K. Straub, "Preparation and catalytic oxidizing potential of polymer supported chelating amine and Schiff base complexes." J. Am. Chem. Soc. 1980; 102:1033-1038.

[9] L. Canali, E. Cowan, C. L. Gibson, D. C. Sherrington, H. Delueze, "Remarkable matrix effect in polymer supported Jacobson's alkene epoxidation catalysts." Chem. Commun. 1998; 23: 2501-2508.

[10] M. Salavati-Niasari, P. Salemi, F. Davar, "Oxidation of cyclo- hexene with tert- butylhydroperoxide and hydrogen per- oxide catalyzed by $\mathrm{Cu}(\mathrm{II}), \mathrm{Ni}(\mathrm{II}), \mathrm{Co}(\mathrm{II})$, and $\mathrm{Mn}(\mathrm{II})$ complexes of N,N'-bis(a-methylsalicylidene) -2,2-dimethyl -2,2-dimethylpropane-1, 3-diamaine, supported on alumina." J. Mol. Catal. A: Chem. 2005; 238: 215-222.

[11] F. AlObaidi, Z. Ye, S. Zhu, "Ethylene polymerization with silica-supported nickel-diimine catalyst: effect of support and polymerization conditions on catalyst activity and polymer properties." Macromol. Chem. Phys. 2003; 204: $1653-1659$.

[12] A. Casagrande, T. Tavares, M. C. A Kuhn, O. L Casagrande, HZ S. Joao, T. Teranishi "Tris(pyrazolyl) borate imido vanadium (V) compound immobilized on inorganic supports and its use in ethylene polymerization." J. Mol. Catal. A: Chem. 2004; 212:267-275.

[13] R-M. Wang, Z-L. Zhang, J-F. Lou, Y-P. Wang, P-F. Song, C-G. Xia. "Preparation and catalytic oxidation properties of inor- ganic polymer encapsulated metal complexes." Polym. Adv. Technol. 2004;15: 48-51.

[14] A. Fuerte, M. Iglesias, F. Sanchez, A..Corma "Chiral dioxomo- lybdenum(VI) and oxovanadium(V) complexes anchored on modified USY-zeolite and mesoporous MCM-41 as solid selective catalyst for oxidation of sulfides or sulfones." J. Mol. Catal A: Chem. 2004; 211: 227-235.

[15] B. Daniela, SF. Chiarello, JH. Zimnoch dos Santos. "Effect of MAO silica surface loading on $(\mathrm{nBuCp}) 2 \mathrm{ZeCl} 2$ anchoring on catalyst actvity and on polymer properties." Appl. Catal. A: Gen. 2004; 261: 57-67.

[16] K. C. Gupta, A. K. Sutar, "Polymer supported catalysts for oxidation of phenol and cyclohexene using hydrogen peroxide as oxidant." J. Mol. Catal. A: Chem. 2008; 280:173-185.

[17] I. Owsik, BN. Kolarz, J. Jezierska, "Oxidation of 2,6-ditertbutylphenols to diphenoquinones catalyzed by sciff base-Cu(II) systems immobolized on polymer support." J. Catal. Lett. 2006; 107: 197-203.

[18] C. Wang, W. Xin, X. Fu, Y. Zhang, Y. Yang, "Studies on catalytic polarographic hydrogen wave in iridium(IV)-cysteine- hydrochloric acid and its application." Fenxi Huaxue 1992; 20: 368-372.

[19] K. C. Gupta, A. K. Sutar, "Polymer anchored Schiff base complexes of transition metal ions and their catalytic activities in oxidation of phenol." J. Mol. Catal. A: Chem. 2007; 272: 64-74.

[20] K. C. Gupta, A. K. Sutar, "Polymer supported Schiff base complexes of Iron(III), Cobalt(II) and Nickel(II) ions and their catalytic activity in oxidation of phenol and cyclohexane." J. Macro mole. Sci. Part A: Pure and Appl. Chem. 2007; 44:1171-118535.

[21] Vogel AI. Textbook of Practical Organic Chemistry, 1978. 